\title{
Salting-out assisted liquid-liquid extraction for the determination of ciprofloxacin residues in water samples by high performance liquid chromatography-diode array detector
}

\author{
Teshome Gezahegn ${ }^{1}$, Bisratewongel Tegegne ${ }^{1,2}$, Feleke Zewge $^{1}$ and Bhagwan Singh Chandravanshi ${ }^{*}$
}

\begin{abstract}
Background: The occurrence of emerging pollutants like pharmaceuticals and related compounds in the aquatic and terrestrial environments is of increasing concern. Ciprofloxacin is one of the pharmaceuticals which is active against a wide range of bacteria. The main objective of this research is to develop a simple method for the extraction and determination of ciprofloxacin residues in environmental water samples.

Results: A salting-out assisted liquid-liquid extraction (SALLE) method for the determination of ciprofloxacin in water samples by high-performance liquid chromatography with diode array detector (HPLC-DAD) was developed. The calibration curve was linear over the range of $0.1-100 \mu \mathrm{g} / \mathrm{L}$ with coefficient of determination $\left(r^{2}\right)$ of 0.9976 . The limits of detection (LOD) and quantification (LOQ) of the method were 0.075 and $0.25 \mu \mathrm{g} / \mathrm{L}$, respectively. The reproducibility in terms of relative standard deviation (\% RSD) was less than $10 \%$. The applicability of the developed method was investigated by analyzing tap water, bottled mineral water and waste water and demonstrated satisfactory recoveries in the ranges of $86.4-120 \%$.

Conclusion: The method offered a number of features including wide linear range, good recovery, short analysis time, simple operation process and environmental friendly. The developed method can be utilized as an attractive alternative for the determination of ciprofloxacin residues in environmental water matrices.

Keywords: Emerging pollutants, Pharmaceuticals, Ciprofloxacin, Salting-out assisted liquid-liquid extraction, Potable water, Wastewater, High performance liquid chromatography-diode array detector
\end{abstract}

\section{Introduction}

Pharmaceuticals are molecules designed to produce a therapeutic effect both in human and veterinary. Pharmaceuticals contain active ingredients that have been designed to have pharmacological effects and confer significant benefits to society. However, their continuous large-scale consumption and the subsequent release in the environment can be proven fatal for animals and plants. Pharmaceuticals are considered a class

\footnotetext{
*Correspondence: bscv2006@yahoo.com

${ }^{1}$ Department of Chemistry, College of Natural Sciences, Addis Ababa University, P.O. Box 1176, Addis Ababa, Ethiopia

Full list of author information is available at the end of the article
}

of emerging contaminants that have raised great concern in the last few years [1-3]. They are continuously being released in the environment mainly due to insufficient removal (70-80\%) in wastewater treatment plants (WWTPs), whereas the remaining $20-30 \%$ is due to other sources of pollution, such as livestock and industrial wastes, hospital effluents and disposal of unused or expired pharmaceuticals $[4,5]$. They are present in various water bodies because up to $95 \%$ of the dose can be excreted or discharged directly into domestic wastewater $[6,7]$.

Research has shown that these compounds are not effectively removed during conventional wastewater treatment; therefore they are released into the surface 
waters, as mixtures of parent compounds, their metabolites and transformation by-products. Some pharmaceuticals can persist in the environment and, either via the food chain or via drinking water, can make their way back to humans, while the properties and fate of metabolites and transformation products are still largely unknown $[8$, 9].

The occurrence of pharmaceutically active compounds in the environmental water has been confirmed with the concentrations usually range at the $\mu \mathrm{g} / \mathrm{L}$ to $\mathrm{ng} / \mathrm{L}$ range in surface waters [10]. In recent years, pharmaceuticals have received growing attention from environmental and health agencies all over the world owing to recent studies showing the occurrence of pharmaceutical compounds in the environment, especially in water bodies and have become one of the emerging water pollutants [11]. The occurrence of pharmaceuticals in wastewater and environmental samples is highly dependent on local diseases, treatment habits and market profiles, thus, the pollution profile can vary significantly between different countries [12]. Pharmaceuticals in water can have potentially toxic effects on the environment and human [13]. However, pharmaceuticals are not included in the models for the assessment of water quality index $[14,15]$.

Antibiotics are among the pharmaceuticals most commonly used in health care systems but the prescription is mostly made on an empirical basis by prescribing broad-spectrum antibiotics [16, 17]. Ciprofloxacin [1-cyclopropyl-6-fluoro-1,4-dihydro-4-oxo-7(1-piperazinyl)-3-quinolone carboxylic acid] (Fig. 1) is a synthetic fluoroquinolone derivative which has demonstrated broad-spectrum activity against many pathogenic gram-positive bacteria such as Streptococcus, Pneumoniae and Enterococcus faecalis, and gram-negative bacteria including Salmonella, Shigella, Campylobacter, Neisseria and Pseudomonas. The bacterial action of ciprofloxacin results from interference with enzyme DNA gyrase which is needed for the synthesis of bacterial DNA

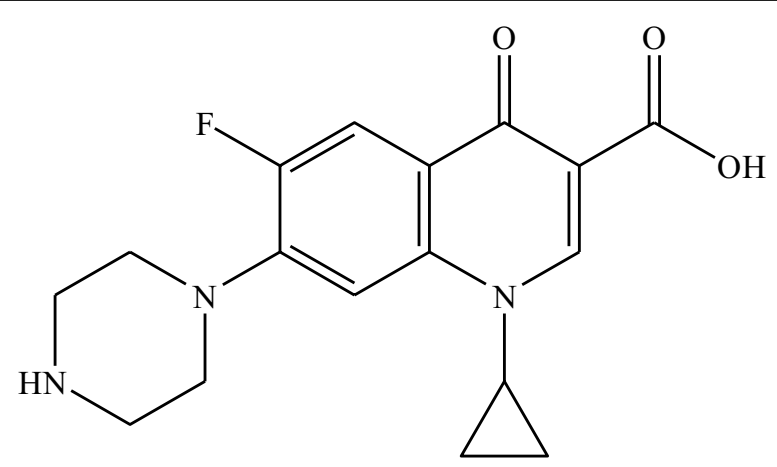

Fig. 1 Structure of ciprofloxacin
$[18,19]$. It is widely used in the treatment of urinary tract infections, lower respiratory tract infections, bacterial diarrhea, skin and soft tissue infections, bone and joint infections, gonorrhea, and in surgical prophylaxis. Physicians prescribe ciprofloxacin as a first choice of drug [20].

Ciprofloxacin have an amino group (piperazinyl) in the heterocyclic ring and have two dissociation constants. The reported $\mathrm{pK}_{\mathrm{a}}$ values of ciprofloxacin are 5.76 (acidic) and 8.68 (basic). They are in their zwitterion form in neutral condition and in cationic form in acidic condition $[21,22]$.

It is very important to have information on the physical and chemical properties of an analyte (e.g., $\log \mathrm{K}_{\mathrm{ow}}, \mathrm{pK}_{\mathrm{a}}$ ) because that may help to determine whether a compound is likely to concentrate in some specific conditions. Log $\mathrm{K}_{\mathrm{ow}}$ is an indicator of the lipophilicity of the compound, high $\log K_{o w}$ is typical for hydrophobic compounds, whereas a low $\mathrm{K}_{\mathrm{ow}}$ signifies a compound soluble in water. Most pharmaceuticals have acidic and/or basic functionalities; their ionization rate depends on acidic dissociation constants (i.e. $\mathrm{pK}_{\mathrm{a}}$ values) and is controlled by solution $\mathrm{pH}$ (e.g., $\mathrm{pK}_{\mathrm{a} 1}$ and $\mathrm{pK}_{\mathrm{a} 2}$ values for certain fluoroquinolones (i.e. ciprofloxacin) are in the ranges 5.7 to 6.3 for carboxylic group and 7.6 to 8.3 for protonated amino group, respectively) [23].

Determination of pharmaceuticals in different water samples can be performed by various chromatographic techniques, including HPLC-UV [24], HPLC-DAD [25, 26], LC-MS [27], LC-MS/MS [28, 29] and GC-MS [30, 31]. HPLC is the most common method used for separation and determination of these compounds because most pharmaceuticals are non-volatile [12]. As the residue of pharmaceutical compounds is usually present at very low concentrations in the environmental water, a sample preparation and pre-concentration step are necessary before analysis [23, 32]. Several procedures have been reported for the pre-concentration of pharmaceuticals from water matrices including solid phase extraction (SPE) [27, 33], liquid-liquid extraction (LLE) [34], QuEChERS method [35], magnetic solid phase extraction (MSPE) [36], hollow fiber liquid phase microextraction [37] and salting-out assisted liquid-liquid extraction for non-steroid anti-inflammatory drugs (NSAIDs) [38]. Each of these methods has its own advantages and disadvantages.

Salting-out assisted liquid-liquid extraction [19] is based on the phase separation of water-miscible organic solvents from the aqueous solutions in the presence of high concentration of salts. It uses water-miscible organic solvents which generally have low toxicity as the extractants, and the use of salts causes almost no pollution to the environment $[19,39]$. Having such benefits, salting out assisted liquid-liquid extraction was selected 
to extract ciprofloxacin from water sample in the present study. The objective of this study was the optimization of analytical parameters for the extraction by SALLE and determination of common antibiotic ciprofloxacin residues in water samples using HPLC-DAD.

\section{Materials and methods Chemicals and reagents}

All the chemicals used in this study were of analytical grade. Standard ciprofloxacin (99\%) was obtained from Addis Pharmaceutical Factory PLC (Ethiopia). HPLC grade methanol (Carlo Erba, Rodano, Italy, HPLC grade, $>99.9 \%$ ), acetonitrile (Sigma-Aldrich, for HPLC, UV and GC, > 99\%), acetic acid (Fisher Chemical UK, 99\%), ammonium solution (Fisher Chemical UK, 35\%), ethyl acetate (Fine Chem Industries, Mumbai, $>99 \%$ ), formic acid (Sigma-Aldrich, 85\%) and ethanol (Fisher Scientific, UK, 99.9\%) were used as received. The different salts used were magnesium sulfate (Fine Chem Industries, Mumbai, $70 \%$ ), sodium chloride (Sigma-Aldrich, 99.5\%), ammonium acetate (BDH Chemical Ltd, England, 96\%), and sodium acetate anhydrous (BDH Chemical Ltd, England, 96\%). Distilled water was used throughout the study.

\section{Instrumentation}

The HPLC system used in the present study was Agilent 1200 Series equipped with Quaternary Pump, Agilent 1200 Series Vacuum Degasser, Agilent 1200 Series Autosampler and Agilent 1200 Series Diode Array Detector Purchased from Agilent Technologies (Hewlett-Packard Strasse Waldbronn, Germany). Chromatographic separation of the compounds was performed on a C18 analytical column (Techsphere 5ODS, $25 \mathrm{~cm} \times 4.6 \mathrm{~mm}$ ID; HPLC Technology, Macclesfield, Cheshire, UK). Data acquisition and processing were accomplished with LC Chemstation software (Agilent Technologies). Adwa $\mathrm{pH}$ meter (AD1020 pH/mV/ISE/Temperature, Hungary) was used for the determination of the sample $\mathrm{pH}$ and $\mathrm{A} 800$ model centrifuge, China, was used to speed up the phase separation. An electronic balance (Adam Equipment Company, UK) was utilized for weighing the different chemicals involved in the experiments. For the measurement of total dissolved solids (TDS) and electrical conductivity, conductivity meter (Postfach 24 80, Germany) was used.

\section{Preparation of standard solutions}

Stock solutions of the ciprofloxacin $(20 \mu \mathrm{g} / \mathrm{mL})$ were prepared in distilled water and stored at $4{ }^{\circ} \mathrm{C}$. Spiked distilled water samples were prepared with the analyte at a known concentration $(0.1 \mu \mathrm{g} / \mathrm{mL})$ to study the extraction performance of salting-out assisted liquid-liquid extraction under different conditions.

\section{Extraction procedure}

The sample solution $(10 \mathrm{~mL})$ was first spiked with a predetermined volume of the standard solution containing the target analyte and quantitatively transferred to each of the $15 \mathrm{~mL}$ screw-capped polyethylene test tubes. Then, $5 \mathrm{~mL}$ acetonitrile and $4 \mathrm{~g} \mathrm{MgSO}_{4}$ were added. Thereafter, the solution was shaken gently for 6 min to ensure complete dissolution of the salt. This was followed by centrifugation of the solution at $4000 \mathrm{rpm}$ for $5 \mathrm{~min}$ which resulted in phase separation. The upper organic phase was carefully withdrawn using micro-syringe and the extract was dried under a steady stream of nitrogen gas and reconstituted using distilled water $(1 \mathrm{~mL})$ and then transferred to a vial for subsequent injection to the HPLC-DAD system. The schematic flow chart of the extraction procedure is given in Scheme 1.

\section{Method evaluation}

The developed SALLE method combined with HPLCDAD was validated utilizing matrix-matched calibration

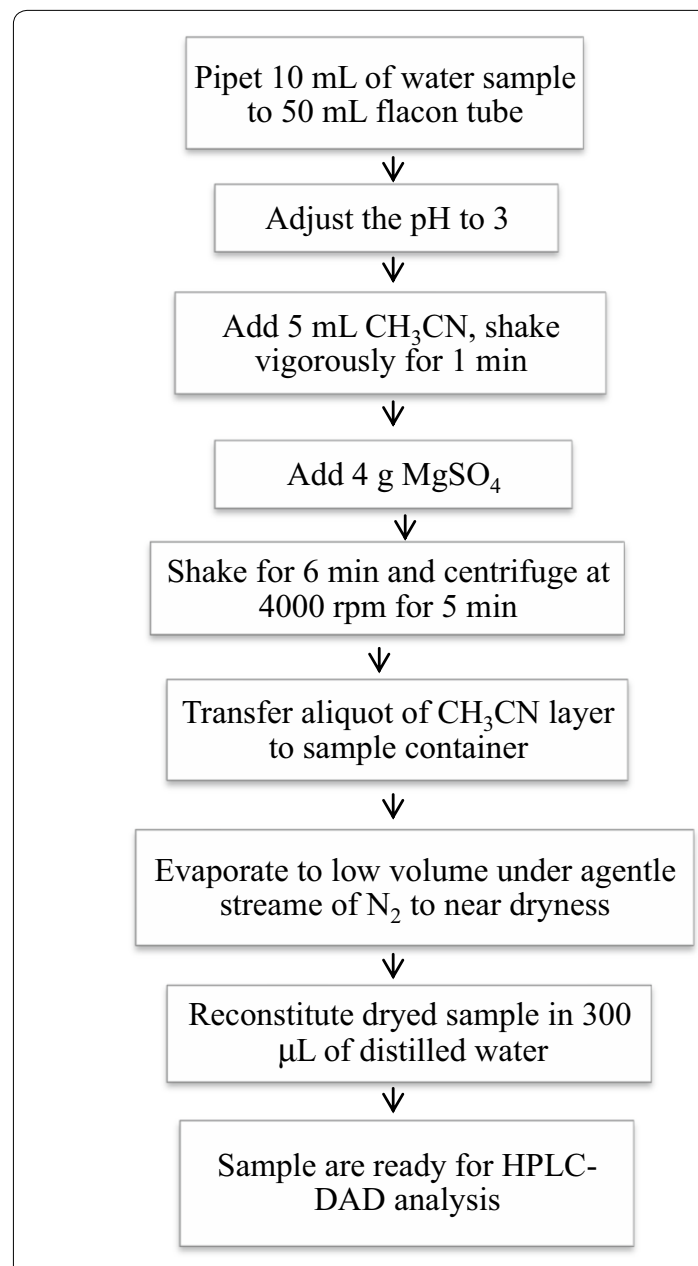

Scheme 1 Flow chart of SALLE for the determination of ciprofloxacin 
curves, linearity, detection limits and intra- and interday precisions. The intra-day repeatability was studied for three replicate experiments and the inter-day repeatability was investigated for three consecutive days at optimized extraction condition for an aqueous sample containing $0.1 \mu \mathrm{g} / \mathrm{mL}$ of ciprofloxacin. The linearity was investigated over a concentration range by plotting corresponding HPLC peak areas versus concentrations of studied analyte. Limits of detection (LOD) and quantification (LOQ) were calculated at signal to noise ratio of 3 and 10 times, respectively.

\section{Environmental water samples}

Environmental water samples $(1 \mathrm{~L}$ each) were collected from wastewater samples from two pharmaceutical industries (PIW1 and PIW2), hospital wastewater (HWW), Addis Ababa Sewerage Treatment Plant (AASTP) and river water (RW) in $1 \mathrm{~L}$ amber colored glass bottles. Immediately after the arrival of the sample to the laboratory some physic-chemical parameters like electrical conductivity, $\mathrm{pH}$, total dissolved solids (TDS) and salinity of the water samples were examined. Before the experiment, all the water samples were filtered through $0.45 \mu \mathrm{m}$ filter paper and stored in amber colored bottles at $4{ }^{\circ} \mathrm{C}$ in the refrigerator.

\section{Chromatographic operating conditions}

The optimum mobile phase composition utilized throughout the chromatographic analysis was $0.1 \%$ formic acid in water/acetonitrile $(70: 30, \mathrm{v} / \mathrm{v})$ at a flow rate of $0.9 \mathrm{~mL} / \mathrm{min}$ in isocratic mode. The column temperature was maintained at $35{ }^{\circ} \mathrm{C}$ and the detector was adjusted at the optimum detection wavelength of $277 \mathrm{~nm}$ with a bandwidth of $4 \mathrm{~nm}$. An aliquot of $20 \mu \mathrm{L}$ of the extracted sample was injected into the HPLC column automatically and eluted for $10 \mathrm{~min}$ run time and $2 \mathrm{~min}$ post-time. Finally, the peak area was utilized as an instrumental response and the analysis was obtained under the aforementioned chromatographic conditions.

\section{Statistical analysis}

All the measurements were done in triplicate. The data were analyzed using statistical software (SPSS Version $21)$. The results are reported as mean \pm SD. Differences were considered significant when $\mathrm{p}<0.05$. The graphical expression was done using Microsoft excel 7.

\section{Result and discussion}

\section{Selection of extraction solvent}

Five organic solvents namely methanol, acetone, acetonitrile, diethyl ether, and ethyl acetate were examined as extraction solvent. The extraction capabilities of these solvents are depicted in (Table 1). It can be

\begin{tabular}{|c|c|c|}
\hline Extraction solvent & $\begin{array}{l}\text { Phase separation } \\
\text { during extraction }\end{array}$ & Peak of analyte \\
\hline Acetonitrile & Partition on the addition of salt & Observed \\
\hline Acetone & $\begin{array}{l}\text { No partition and salt did not } \\
\text { dissolved }\end{array}$ & Not observed \\
\hline Diethyl ether & Partition before addition of salt & No observed \\
\hline Ethyl acetate & Partition before addition of salt & No observed \\
\hline Methanol & $\begin{array}{l}\text { No partition and salt did not } \\
\text { dissolved }\end{array}$ & No observed \\
\hline
\end{tabular}

seen that under the same extraction condition, acetonitrile provided the best results with the only peak of the selected analyte. The other solvents used did not show any peak in the retention time of the target analyte (ciprofloxacin) in the chromatogram. The first two solvents, i.e. methanol and acetone are completely miscible with water and they were unable to produce phase separation at all after centrifugation. Hence they were not taken as candidates for further comparison. However, the last two, diethyl ether and ethyl acetate produced the phase separation before the addition of salt. Hence additional comparison steps were carried out for these three solvents which gave clear phase separation. From the three solvents, only acetonitrile showed the peak of the analyte in the chromatogram and it was selected as an extraction solvent. As it was reported [40], acetonitrile is miscible with water in any proportion at room temperature, lowering the temperature or addition of salt significantly reduced the mutual miscibility, even resulting in phase separation of acetonitrile from the aqueous phase. The other two solvents diethyl ether and ethyl acetate did not showed any peak in the chromatogram presumably because they could not extract the analyte due to their lower polarity than acetonitrile.

\section{Effect of volume of extraction solvent}

After acetonitrile was selected as the extraction solvent, its volume was optimized using the same extraction condition. The volume of 5, 10 and $15 \mathrm{~mL}$ of acetonitrile was used for the selection of the optimum volume for the analyte extraction from $10 \mathrm{~mL}$ of sample. As shown in (Fig. 2), maximum peak area was obtained when the volume was $5 \mathrm{~mL}$. When the volume of acetonitrile was below $5 \mathrm{~mL}$, the phase separation was not easy and it was very difficult to take the upper organic phase separately. Similarly, at higher volumes of acetonitrile, above $5 \mathrm{~mL}$, the volumes of the upper organic phase get increased but decreasing the analyte enrichment by dilution and hence further higher volumes were not examined. 


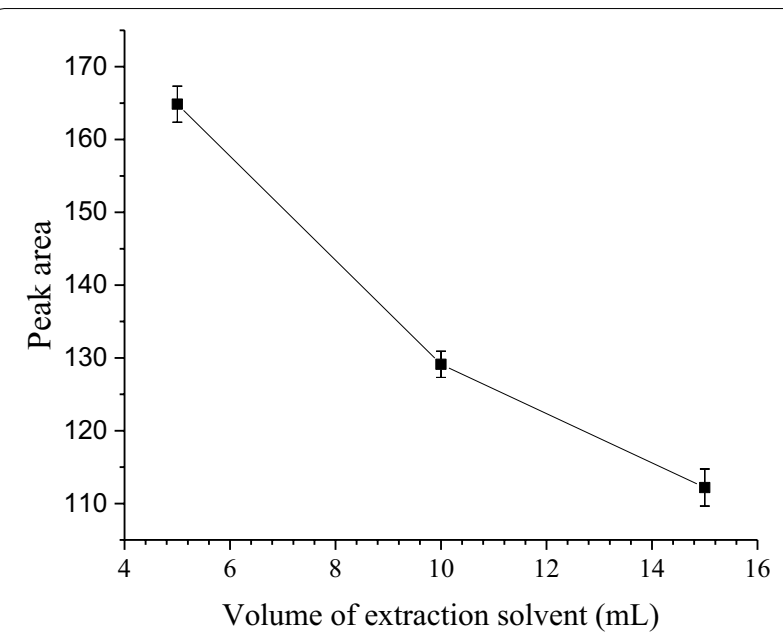

Fig. 2 Effect of volume of extraction solvent on the SALLE efficiency

\section{Effect of sample solution $\mathrm{pH}$}

The $\mathrm{pH}$ value is important as it affects the ionization status as well as the solubility of the analytes $[41,42]$. For efficient extraction of ionizable and relatively polar compounds, $\mathrm{pH}$ of the sample solution plays a decisive role. The sample solution $\mathrm{pH}$ should be lower than the $\mathrm{pK}_{\mathrm{a}}$ of the analytes to obtain the target analytes in their unionized forms so that they have a higher tendency to partition into the organic phase [43]. The effect of varying $\mathrm{pH}$ values of the sample solution on the extraction efficiency was studied in the range of 3.0-8.0. The results are depicted in (Fig. 3), which demonstrated that the extraction efficiency decreased by increasing the $\mathrm{pH}$ up to about 8.0. Therefore, the $\mathrm{pH}$ value of 3.0 was selected for the extraction of ciprofloxacin.

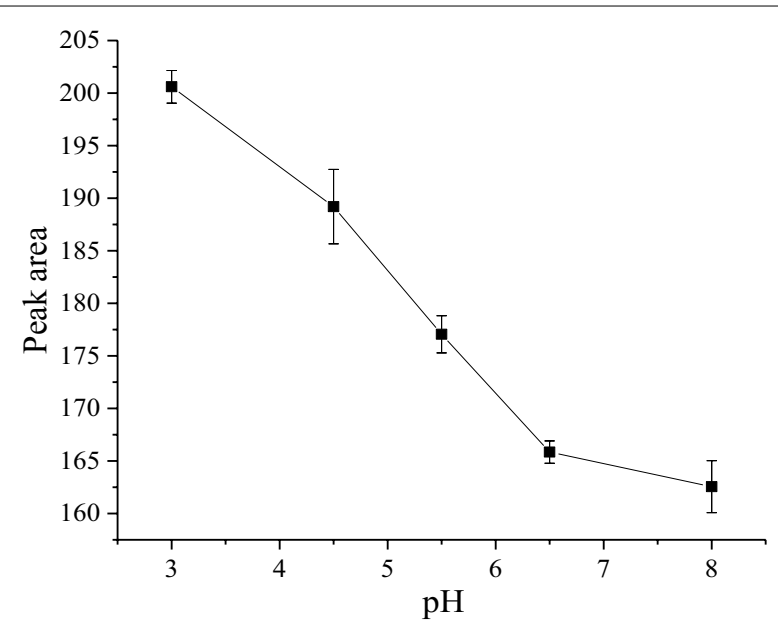

Fig. 3 Effects of pH on the SALLE efficiency
When a water sample is acidified to a $\mathrm{pH}$ that is less than the $\mathrm{pK}_{\mathrm{a}}$ value of target compounds, the acids are non-ionized which leads to their adsorption through the reversed-phase interactions. At acidic conditions they are in cationic form, which is important for their retention during the extraction. At basic conditions, the anionic species of both acidic and piperazinylic quinolones are less retained in comparison to cationic, zwitterionic and neutral species $[43,44]$.

\section{Effect of type and amount of the salt}

Different salts and different salt concentrations cause different degrees of phase separation. The effect of ionic strength was extensively evaluated in traditional liquidliquid extraction. The addition of a salt is often used to decrease the solubility of hydrophilic compounds in the aqueous phase through a salting-out effect and consequently increase the partition of analytes into the organic phase [19]. In order to obtain phase separation and the optimum extraction efficiency, several salts with different combinations $\left(\mathrm{MgSO}_{4}, \mathrm{MgSO}_{4}\right.$ with $\mathrm{NaCl}, \mathrm{MgSO}_{4}$ with $\mathrm{NH}_{4} \mathrm{OAC}$, and $\mathrm{MgSO}_{4}$ with $\mathrm{NaOAC}$ ) were examined (Fig. 4). The results demonstrated that $\mathrm{MgSO}_{4}$ separately provided higher extraction efficiency than the other salts. This may be due to its high ionic strength per unit concentration in the aqueous phase compared to its combination with other salts. It should be pointed out that any strong Lewis base could have interaction with magnesium and impact on the extraction efficiency because magnesium is a strong Lewis acid [40]. Therefore, $\mathrm{MgSO}_{4}$ was selected for further study. Meanwhile, the effect of the amount of $\mathrm{MgSO}_{4}$ on the extraction efficiency was investigated, varied amounts of $\mathrm{MgSO}_{4}$ from 2.0 to $5.0 \mathrm{~g}$ (changed every $1.0 \mathrm{~g}$ ) were added to $15 \mathrm{~mL}$ mixed solution (contained $10 \mathrm{~mL}$ treated sample solution and $5 \mathrm{~mL}$

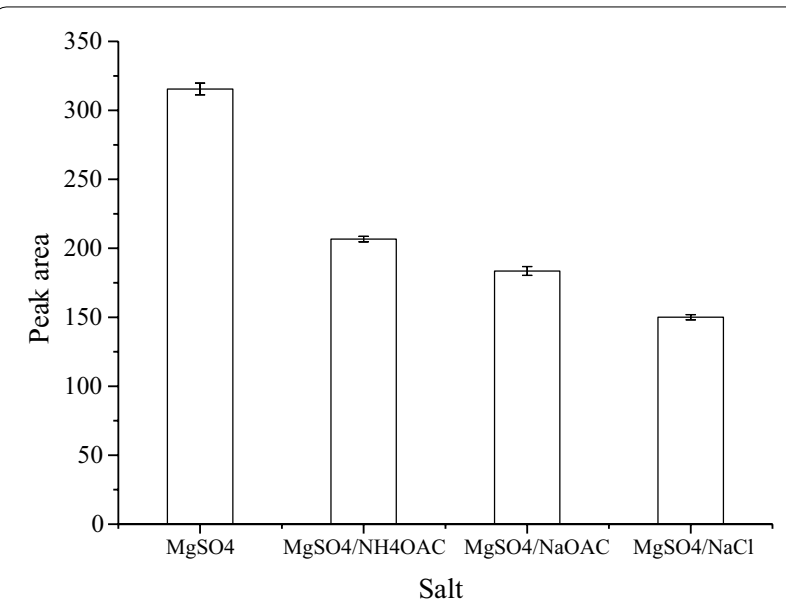

Fig. 4 Effect of salt type on the SALLE efficiency 


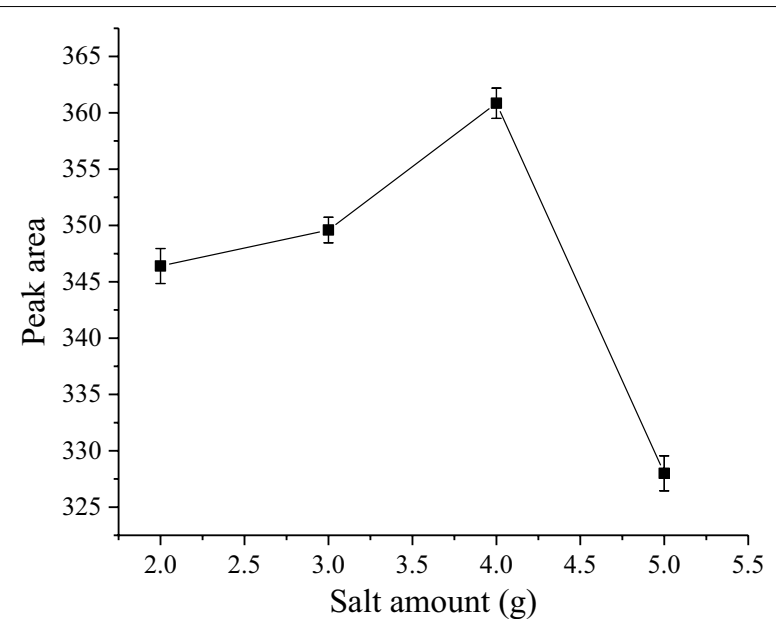

Fig. 5 Effect of the salt amount on the SALLE efficiency

acetonitrile). It is evident from (Fig. 5) that the optimum amount of $\mathrm{MgSO}_{4}$ for the extraction of analysts and the phase separation was considered to be $4 \mathrm{~g}$ at room temperature in a $10 \mathrm{~mL}$ sample solution. At lower amount of $\mathrm{MgSO}_{4}$ the extraction of analyte was not complete while at much higher amount (5 g or more) of $\mathrm{MgSO}_{4}$ might resulted to reverse the extraction of analyte due to increase in polarity of the aqueous phase.

\section{Effect of centrifuge speed}

Centrifugation speed is one of the most important parameters in the sample preparation steps and also plays a key role in the separation of the phases and thus results in a clear solution. In order to obtain the highest signal, the speed was varied from 2000 to $4000 \mathrm{rpm}$. The corresponding experimental results revealed that the peak areas were increasing with the centrifuge speed, up to $4000 \mathrm{rpm}$ (Fig. 6). Hence $4000 \mathrm{rpm}$ were taken as optimum centrifugation speed. Further higher centrifugation speeds were not examined.

\section{Extraction time}

Mass transfer is a time-dependent process and is also factors in most of the extraction procedures. In the present study, the effect of extraction time on the extraction of analyte was investigated over the range of 2-10 min. The experimental results revealed that 6 min extraction time was found to be optimum. This may be attributed to the very fast mass transfer taking place initially but before the establishment of the equilibrium state, which was achieved later, around 6 min (Fig. 7). Therefore, extraction time of 6 min was found to be the optimum time and used throughout this study. Longer extraction time resulted in decrease of analyte extraction. This might

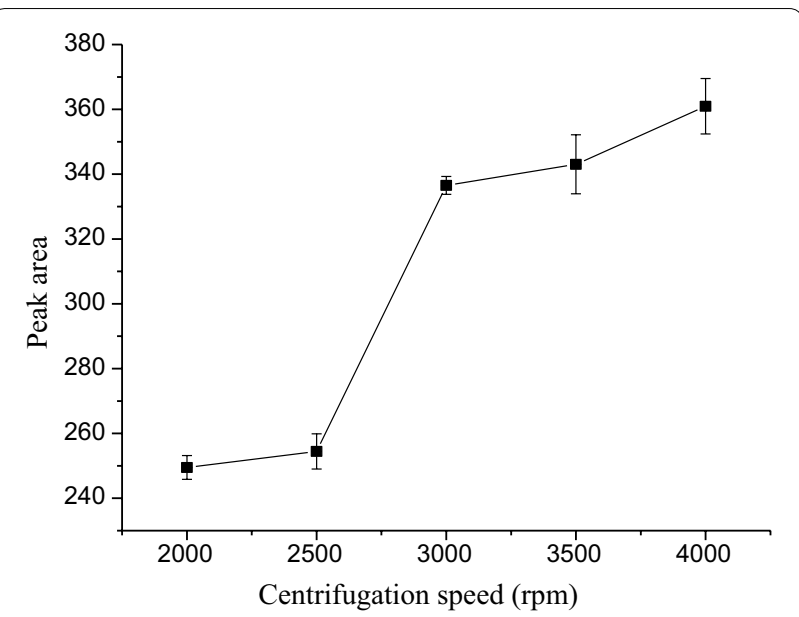

Fig. 6 Effect of centrifuge speed on the SALLE efficiency

be due to higher miscibility of the two phases at longer extraction (contact) time.

Selected physicochemical parameters of water samples Physicochemical parameters are evaluated to determine the degree of contaminants in the water that can affect the water quality and consequently the human health [45]. These are evaluated usually based on scientifically assessed acceptable levels of toxicity to either humans or aquatic organisms [46]. Selected physicochemical parameters of the environmental water samples collected for the determination of ciprofloxacin antibiotic were determined and are presented in Table 2. From all the water samples analyzed, river water was found to have the highest value in conductivity, TDS and salinity than the rest of the water samples. Hospital wastewater showed basic $\mathrm{pH}$ and the others are comparably neutral.

\section{Validation of the method}

The analytical characteristics of the proposed method were determined under the optimal conditions. The analyte (ciprofloxacin) showed a single characteristic peak at retention time of about $0.333 \mathrm{~min}$. The calibration curves were established by analyzing the extract of the spiked water sample with the analyte at five different concentration levels. Each level was extracted in triplicate and each extract was analyzed. The calibration curve was obtained by plotting the peak areas versus concentration of the analyte. The results obtained revealed that the calibration curve was linear in the concentration range $0.1-100 \mu \mathrm{g} / \mathrm{L}$. The coefficients of determination $\left(R^{2}\right)$ for the analyte was higher than 0.9976 , indicating good linearity over the studied concentrations range. The limits of detection (LOD) and quantification (LOQ) were determined as the minimum analyte concentration yielding three and ten 


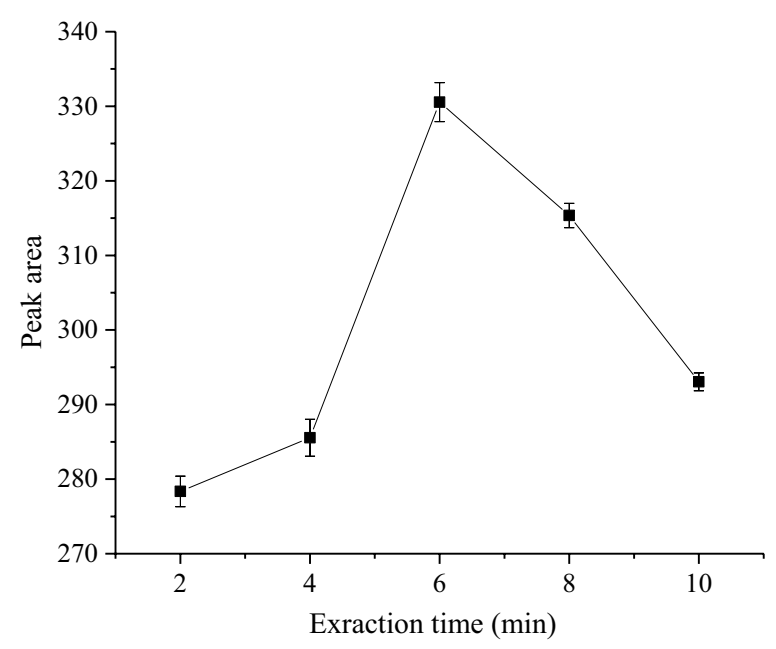

Fig. 7 Effect of extraction time on the SALLE efficiency

Table 2 Physicochemical parameters of the environmental water samples

\begin{tabular}{lcccl}
\hline Sample & $\mathbf{p H}$ & TDS $(\mathbf{m g} / \mathbf{L})$ & $\begin{array}{l}\text { Conductivity } \\
(\boldsymbol{\mu} \mathbf{S})\end{array}$ & Salinity (0/00) \\
\hline HWW & 8.8 & 232 & 485 & 0.2 \\
RW & 7.5 & 2160 & 4240 & 2.2 \\
PIW1 & 6.8 & 209 & 441 & 0.2 \\
PIW2 & 6.4 & 315 & 656 & 0.3 \\
AASTP & 7.4 & 543 & 1128 & 0.5 \\
\hline
\end{tabular}

$H W W$ hospital wastewater, $R W$ river water, $P I W$ pharmaceutical industry waste, AASTP Addis Ababa Sewerage Treatment Plant

times the signal to noise $(\mathrm{S} / \mathrm{N})$ ratio, respectively. Thus, LOD was $0.075 \mu \mathrm{g} / \mathrm{L}$ and the LOQ was $0.25 \mu \mathrm{g} / \mathrm{L}$. Precision was demonstrated by determining the inter- and intra-day relative standard deviation (\% RSD) of the analysis with $0.1 \mu \mathrm{g} / \mathrm{mL}$ spiked water sample. The intraday precision was evaluated by analyzing the spiked samples in the same day and the RSD was found to be $1.7 \%$ while inter-day precision was performed for 3 days and the RSD obtained was $6.9 \%$ which are in the acceptable range. This further indicates that the short retention time did not make an issue in day to day sample analysis.

\section{Application to environmental water samples}

In order to investigate the applicability of the proposed SALLE method, recovery experiments were carried out on four kinds of water samples of different origin spiked with different concentration of ciprofloxacin. The recovery results as shown in Table 3 ranged from 86.4 to $120 \%$. Ciprofloxacin was not detected in tap water, bottled mineral water, and hospital wastewater. It was detected only in the waste water from Addis Ababa Sewage Treatment
Table 3 Recovery results of different water matrices

\begin{tabular}{llll}
\hline Types of sample & $\begin{array}{l}\text { Spiked level } \\
(\boldsymbol{\mu g} / \mathbf{m L})\end{array}$ & \% RSD & Recovery (\%) \\
\hline Distilled water & 0 & - & - \\
& 2.5 & 0.79 & 101 \\
Tap water & 5 & 2.47 & 103 \\
& 0 & - & - \\
& 0.02 & 2.78 & 100 \\
Bottled water & 0.1 & 5.50 & 120 \\
& 2.5 & 0.66 & 86.4 \\
& 0 & - & - \\
Hospital wastewater & 0.1 & 1.27 & 108 \\
& 2.5 & 1.82 & 91.2 \\
& 0 & - & - \\
\hline
\end{tabular}

Plant (AASTP). This could be due to either the water samples analyzed other than wastewater from AASTP, were free from the residues of target pharmaceutical or contained concentrations below the detection limits. The obtained ciprofloxacin concentration in the wastewater sample from sewerage treatment plant was $0.83 \mu \mathrm{g} /$ $\mathrm{mL}$. This might be because the sewerage treatment plant collects wastes from many toilets from the city. Like many studies, result reveals that most pharmaceuticals found in the wastewater as parent compound and/or its metabolites via excretion, mainly in urine $(55-80 \%)$ and to a lesser extent in feces $(4-30 \%)$ [47, 48]. Typical chromatograms of the non-spiked wastewater and spiked wastewater $(0.1 \mu \mathrm{g} / \mathrm{mL})$ samples from Addis Ababa Sewage Treatment Plant using the optimized SALLE-HPLC technique are shown in Fig. 8.

\section{Comparison of present method with the other methods reported in literature}

The important analytical parameters of the proposed SALLE-HPLC-DAD method for the determination of ciprofloxacin antibiotic residue were compared to some of the previously reported methods and the data are summarized in Table 4. The proposed method has good and comparable analytical results compared with other methods for extraction and determination of ciprofloxacin in different matrices. Based on the experimental findings the proposed technique has wider linear range and lower limit of detection and quantification compared to others work $[49,50]$. In addition, the present method has better values of correlation coefficient $\left(R^{2}\right)$ and better recovery than the most of the reported methods [35, 51]. However, the present method has higher detection limit and less sensitive than the reported methods based on mass spectrometry detector. But the present method has advantage 

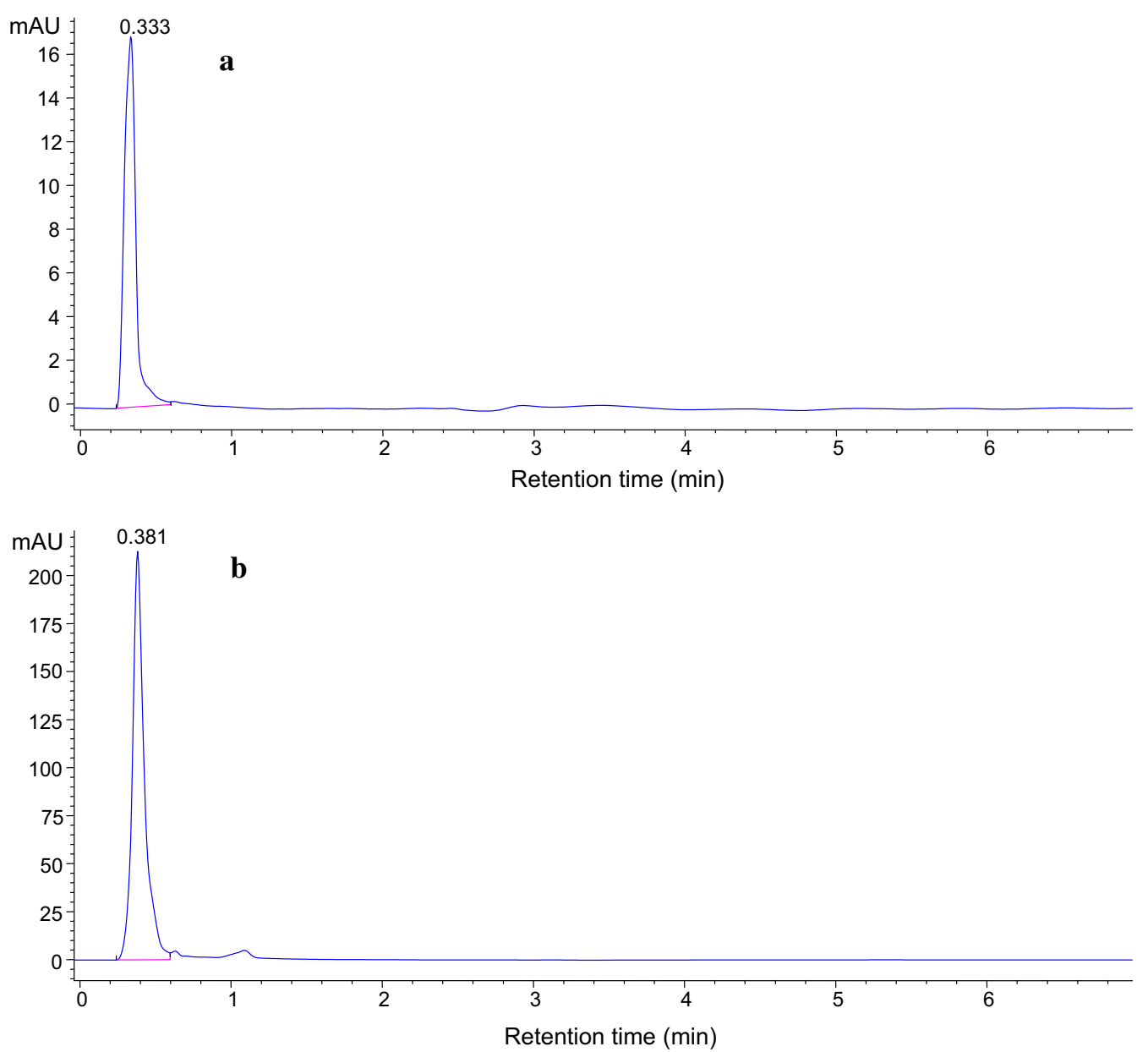

Fig. 8 Typical representative chromatogram of $\mathbf{a}$ unspiked and $\mathbf{b}$ spiked wastewater. Extraction conditions: $10 \mathrm{~mL}$ spiked at $0.1 \mu \mathrm{g} / \mathrm{mL}$; volume of acetonitrile, $5 \mathrm{~mL}$; amount of salt added, $4 \mathrm{~g} \mathrm{MgSO}_{4}$; extraction time, $6 \mathrm{~min} ; \mathrm{pH}$ of the sample solution, 3; centrifugation speed, $4000 \mathrm{rpm} ; \mathrm{n}=3$

Table 4 Comparison between the proposed SALLE-HPLC-DAD method and some reported methods for the determination of ciprofloxacin in deferent matrices

\begin{tabular}{|c|c|c|c|c|c|c|}
\hline Analytical method & Linear range $\mu \mathrm{g} / \mathrm{L}$ & $\mathrm{R}^{2}$ & LOD $\mu \mathrm{g} / \mathrm{L}$ & $\mathrm{LOQ} \mu \mathrm{g} / \mathrm{L}$ & $\%$ Recovery & Refs. \\
\hline QuEChERS-LC-MS/MS & $0.01-10$ & 0.9951 & 0.033 & 0.1 & $73-125$ & {$[35]$} \\
\hline SPE-HPLC-MS & $10-1000$ & 0.9981 & - & 0.04 & $89-97$ & {$[50]$} \\
\hline SPE-LC-MS/MS & $0.5-600$ & 0.9935 & 0.001 & 0.003 & $78-98$ & [52] \\
\hline SPE-LC-MS/MS & $0.01-10$ & 0.9968 & 0.001 & 0.01 & $47-117$ & [51] \\
\hline SPE-HPLC-DAD & $0.5-20$ & 0.9991 & 0.25 & 0.5 & $90-110$ & [49] \\
\hline SALLE-HPLC-DAD & $0.1-100$ & 0.9976 & 0.075 & 0.25 & $86-120$ & This work \\
\hline
\end{tabular}

of easy of operation in contrast to other HPLC/MS methods. Therefore, the proposed SALLE-HPLC-DAD can be considered as one of the preferred alternative having a promising future for selective and quantitative extraction of pharmaceutical residue contaminating various environmental water systems.

\section{Conclusion}

A SALLE method coupled with HPLC-DAD was developed and successfully utilized for the determination of ciprofloxacin residue in environmental water. The method offered a number of features including wide linear range, high recovery, and short analysis time, 
simple operation process and environmentally friendly. Based on the present findings SALLE, coupled with a water-miscible extraction solvent, acetonitrile, and $\mathrm{MgSO}_{4}$ as the salting-out agent, could be taken as a significantly promising extraction and pre-concentration method for trace analysis of water-soluble pharmaceutical (ciprofloxacin) residues which are difficult to be extracted with non-polar organic solvents from various environmental water samples. The method has advantages of simplicity, easy operation and short analysis time with consumption of low volume of the less hazardous organic solvent, acetonitrile. Therefore, the developed method can be utilized as an attractive alternative for the determination of antibiotic ciprofloxacin in environmental water matrices.

\section{Abbreviations}

AASTP: Addis Ababa Sewerage Treatment Plant; GC-MS: gas chromatography-mass spectrometry; HPLC-DAD: high-performance liquid chromatography with diode array detector; HPLC-UV: high-performance liquid chromatography with ultraviolet detector; HWW: hospital wastewater; LC-MS: liquid chromatography-mass spectrometry; LC-MS/MS: liquid chromatographymass spectrometry/mass spectrometry; LLE: liquid-liquid extraction; LOD: limit of detection; LOQ: limits of quantification; MSPE: magnetic solid phase extraction; NSAIDs: non-steroid anti-inflammatory drugs; PIW1: pharmaceutical industries wastewater one; PIW2: pharmaceutical industries wastewater two; QuEChERS: Quick Easy Cheap Effective Rugged Safe; QuEChERS-LC-MS/ MS: Quick Easy Cheap Effective Rugged Safe-liquid chromatography mass spectrometry/mass spectrometry; RSD: relative standard deviation; RW: river water; SALLE: salting-out assisted liquid-liquid extraction; SALLE-HPLC-DAD: salting-out assisted liquid-liquid extraction-high-performance liquid chromatography with diode; SPE: solid phase extraction; SPE-HPLC-DAD: solid phase extraction-high-performance liquid chromatography with diode array detector; SPE-HPLC-MS: solid phase extraction-high-performance liquid chromatography-mass spectrometry; SPE-LC-MS/MS: solid phase extraction-highperformance liquid chromatography-mass spectrometry/mass spectrometry; TDS: total dissolved solids; WWTPs: wastewater treatment plants.

\section{Authors' contributions}

FZ and BSC designed the study; TG and BT performed the experiments; TG and BT collected the data and drafted the manuscript; FZ and BSC interpreted the data; BSC edited the manuscript. All authors read and approved the final manuscript.

\section{Author details}

${ }^{1}$ Department of Chemistry, College of Natural Sciences, Addis Ababa University, P.O. Box 1176, Addis Ababa, Ethiopia. ${ }^{2}$ Departement of Chemistry, College of Natural Sciences, Bahir Dar University, P.O. Box 79, Bahir Dar, Ethiopia.

\section{Acknowledgements}

The authors are grateful to the Chemistry Department, Addis Ababa University, Ethiopia for providing laboratory facilities.

\section{Competing interests}

The authors declare that they have no competing interests.

\section{Ethics approval and consent to participate}

Not applicable.

\section{Publisher's Note}

Springer Nature remains neutral with regard to jurisdictional claims in published maps and institutional affiliations.
Received: 17 October 2018 Accepted: 22 February 2019

Published online: 09 March 2019

\section{References}

1. Khan A, Khuda F, Elseman AM, Aly Z, Wang X (2018) Innovations in graphene-based nanomaterials in the pre-concentration of pharmaceuticals waste. Environ Technol Rev 7(1):73-94. https://doi.org/10.1080/21622 515.2018.1457726

2. Ebele AJ, Abdallah MA, Harrad S (2017) Pharmaceuticals and personal care products (PPCPS) in the fresh water aquatic environment. Emerg Contaminants 3:1-16. https://doi.org/10.1016/j.emcon.2016.12.004

3. WHO (2012) Pharmacutical in drinking water. WHO, Geneva

4. Lin AY, YU T, Lin C (2008) Pharmaceutical contamination in residential, industrial, and agricultural waste streams: risk to aqueous environments in Taiwan. Chemosphere 74:131-141. https://doi.org/10.1016/j.chemo sphere.2008.08.027

5. Logarinhoa F, Rosadoa T, Lourenc C, Barrosod M, Araujoc AR, Gallardo E (2016) Determination of antipsychotic drugs in hospital and wastewater treatment plant samples by gas chromatography/tandem mass spectrometry. J Chromatogr B 1038:127-135. https://doi.org/10.1016/j.jchro mb.2016.10.031

6. Bottoni P, Caroli S, Caracciolo AB (2010) Pharmaceuticals as priority water contaminants. Toxicol Environ Chem 92(3):549-565. https://doi. org/10.1080/02772241003614320

7. Baranowska I, Kowalski B (2012) A rapid UHPLC method for the simultaneous determination of drugs from different therapeutic groups in surface water and wastewater. Bull Environ Contam Toxicol 89(1):8-14. https://doi.org/10.1007/s00128-012-0634-7

8. Fatta D, Achilleos A, Nikolaou A, Meric S (2007) Analytical methods for tracing pharmaceutical residues in water and wastewater. Trends Anal Chem 26(6):515-533. https://doi.org/10.1016/j.trac.2007.02.001

9. Jones OA, Lester JN, Voulvoulis N (2005) Pharmaceuticals: a threat to drinking water? Trends Biotechnol 23(4):163-167. https://doi. org/10.1016/j.tibtech.2005.02.001

10. Tran NH, Urase T, Ta T (2014) A Preliminary study on the occurrence of pharmaceutically active compounds in hospital wastewater and surface water in Hanoi. Vietnam. Clean Soil Air Water 42(3):267-275. https://doi. org/10.1002/clen.201300021

11. Kumar A, Xagoraraki I (2010) Pharmaceuticals, personal care products and endocrine-disrupting chemicals in U.S. surface and finished drinking waters: a proposed ranking system. Sci Total Environ 408(23):5972-5989. https://doi.org/10.1016/j.scitotenv.2010.08.048

12. Salgado R, Noronha JP, Oehmen A, Carvalho G, Reis MA (2010) Analysis of 65 pharmaceuticals and personal care products in 5 wastewater treatment plants in Portugal using a simplified analytical methodology. Water Sci Technol 62(12):2863-2871. https://doi.org/10.2166/wst.2010.985

13. Alshakka M, Ibraim Ml, Hassali M (2016) Hazards of pharmaceuticals in water as new area in eco-pharmacovigilance research. J Pharm Pract Community Med 2(1):3-8. https://doi.org/10.5530/jppcm.2016.1.2

14. Mohammed SI, Abdulrazzaq KA (2018) Developing water quality index to assess the quality of the drinking water. Civil Eng J 4(10):2345-2355. https ://doi.org/10.28991/cej-03091164

15. Khudair BH, Jasim MM, Alsaqqar AS (2018) Artificial neural network model for the prediction of groundwater quality. Civil Eng J 4(12):2959-2970. https://doi.org/10.28991/cej-03091212

16. Getachew E, Aragaw S, Adissie W, Agalu A (2013) Antibiotic prescribing pattern in a referral hospital in Ethiopia. Afr J Pharm Pharmacol Therap Part B Gen Syst Pharmacol 7(38):2657-2661. https://doi.org/10.5897/ ajpp12.505

17. Worku F, Tewahido D (2018) Retrospective Assessment of Antibiotics Prescribing at Public Primary Healthcare Facilities in Addis Ababa, Ethiopia. Interdiscip Perspect Infect Dis 2018:1-10. https://doi. org/10.1155/2018/4323769

18. Varak M, Ebrahimi M (2018) Preconcentration and determination of ciprofloxacin with solid-phase microextraction and silica-coated magnetic nanoparticles modified with salicylic acid by UV-Vis spectrophotometry. Eurasian J Anal Chem 13(3):1-12. https://doi.org/10.29333/ejac/85176

19. Xia Q, Yang Y, Liu M (2012) Aluminium sensitized spectrofluorimetric determination of fluoroquinolones in milk samples coupled with salting-out 
assisted liquid-liquid ultrasonic extraction. Spectrochim Acta Part A Mol Biomol Spectros 96:358-364. https://doi.org/10.1016/j.saa.2012.05.048

20. Olaitan OJ, Anyakora C, Bamiro T, Tella AT (2014) Determination of pharmaceutical compound in surface and underground water by solid phase extraction-liquid chromatography. J Environ Chem Toxicol 6(3):20-26. https ://doi.org/10.5897/JECE2013.0312

21. Gros M, Mozaz S, Barcelo D (2013) Rapid analysis of multiclass antibiotic residues and some of their metabolites in hospital, urban wastewater and river water by ultra-high performance liquid chromatography coupled to quadrupole-linear ion trap tandem mass spectrometry. J Chromatogr A 1292:173-188. https://doi.org/10.1016/j.chroma.2012.12.072

22. Khattab F, Salem H, Riad S, Elbalkiny H (2014) Determination of fluoroquinolone antibiotics in industrial waste water by high-pressure liquidchromatography and thin layer chromatography-densitometric methods. J Planar Chromatogr 27(4):287-293. https://doi.org/10.1556/JPC.27.2014.4.9

23. Pavlovic DM, Babic S, Alka J, Horvat M, Macan MK (2007) Sample preparation in analysis of pharmaceuticals. Trends Anal Chem 26(11):1062-1075. https:// doi.org/10.1016/j.trac.2007.09.010

24. Silva DC, Oliveira CC (2018) Development of micellar HPLC-UV method for determination of pharmaceuticals in water samples. J Anal Methods Chem 2018. Article ID 9143730. https://doi.org/10.1155/2018/9143730

25. Madureira TV, Rocha MJ, Cass QB, Tiritan ME (2010) Development and optimization of a HPLC-DAD method for the determination of diverse pharmaceuticals in estuarine surfacewaters. J Chromatogr Sci 48:176-182. https://doi.org/10.1093/chromsci/48.3.176

26. Baranowska I, Kowalski B (2011) Using HPLC method with DAD detection for the simultaneous determination of 15 drugsin surface water and wastewater. Polish J Environ Stud 20(1):21-28. https://doi.org/10.1007/s0012 8-012-0634-7

27. Iglesias A, Nebot C, Vázquez B, Coronel-Olivares C, Abuín F, Cepeda A (2014) Monitoring the presence of 13 active compounds in surface water collected from rural areas in Northwestern Spain. Int J Environ Res Public Health 11:5251-5272. https://doi.org/10.3390/ijerph110505251

28. Ort C, Lawrence MG, Reungoat J, Eaglesham G, Carter S, Keller J (2010) Determining the fraction of pharmaceutical residues in wastewater originating from a hospital. Water Res 44(2):605-615. https://doi.org/10.1016/j.watre s.2009.08.002

29. Chen Y, Vymazal J, Březinová T, Koželuh M, Kule L, Huang J, Chen Z (2016) Occurrence, removal and environmental risk assessment of pharmaceuticals and personal care products in rural wastewater treatment wetlands. Sci Total Environ 566-567:1660-1669. https://doi.org/10.1016/j.scito tenv.2016.06.069

30. Farré M, Petrovic M, Barceló D (2007) Recently developed GC/MS and LC/ MS methods for determining NSAIDs in water sample. J Anal Bioanal Chem 387:1203-1214. https://doi.org/10.1007/s00216-006-0936-x

31. Qureshi T, Memon N, Memon SQ, Shaikh H (2014) Determination of ibuprofen drug in aqueous environmental samples by gas chromatography-mass spectrometry without derivatization. Am J Modern Chromatogr 1(1):45-54. https://www.researchgate.net/publication/283122628. Accessed 13 Jan 2019

32. Wille K, Brabander HF, De Wulf E, Caeter PV, Janssen CR, Vanhaecke L (2012) Coupled chromatographic and mass-spectrometric techniques for the analysis of emerging pollutants in the aquatic environment. Trends Anal Chem 35:87-108. https://doi.org/10.1016/j.trac.2011.12

33. Al-Qaim FF, Abdullah P, Othman MR, Latip J, Afiq WM (2013) Development of analytical method for detection of some pharmaceuticals in surface water. Trop J Pharm Res 12(4):609-616. https://doi.org/10.4314/tjpr.v12i4.25

34. Padrón ET, Afonso-Olivares C, Sosa-Ferrera Z, Santana-Rodríguez J (2014) Microextraction techniques coupled to liquid chromatography with mass spectrometry for the determination of organic micropollutants in environmental water samples. Molecules 19:10320-10349. https://doi.org/10.3390/ molecules 190710320

35. Kachhawaha AS, Nagarnaik PM (2017) Optimization of a modified QuEChERS method for multiresidue analysis of pharmaceuticals and personal care products in sewage and surface water by LC-MS/MS. J AOAC Int 100(3):592-597. https://doi.org/10.5740/jaoacint.17-0060

36. Tolmacheva W, Apyari W, Furletov AA, Dmitrienko SG, Zolotov YA (2016) Facile synthesis of magnetic hypercrosslinked polystyrene and its application in the magnetic solid-phase extraction of sulfonamides from water and milk samples before their HPLC determination. Talanta 152:203-210. https://doi.org/10.1016/j.talanta.2016.02.010

37. Sharifi V, Abbasi A, Nosrati A (2016) Application of hollow fiber liquid phase microextraction and dispersive liquideliquid microextraction techniques in analytical toxicology. J Food Drug Anal 24:264-276. https://doi. org/10.1016/j.jfda.2015.10.004

38. Noche G, Laespadab ME, Pavónb JL, Corderob BM, Lorenzoa SM (2011) In situ aqueous derivatization and determination of non-steroidalantiinflammatory drugs by salting-out-assisted liquid-liquid extraction and gas chromatography-mass spectrometry. J Chromatogr A 1218:6240-6247. https://doi.org/10.1016/j.chroma.2011.06.112

39. Alshishania A, Salhimib SM, Saada B (2018) Salting-out assisted liquid-liquid extraction coupled with hydrophilic interaction chromatography for the determination of biguanides in biological and environmental samples. J Chromatogr B 1073:51-59. https://doi.org/10.1016/j.jchromb.2017.12.013

40. Zhang J, Wiley J, Wu H, Kima E, El-Shourbagya TA (2009) Salting-out assisted liquid/liquid extraction with acetonitrile: a new high throughput sample preparation technique for good laboratory practice bioanalysis using liquid chromatography-mass spectrometry. Biomed Chromatogr 23:419-425. https://doi.org/10.1002/bmc.1135

41. Valente IM, Goncalves LM, Rodrigues JA (2013) Another glimpse over the salting-out assisted liquid-liquid extraction in acetonitrile/water mixtures. J Chromatogr A 1308:58-62. https://doi.org/10.1016/j.chroma.2013.08.014

42. Atlabachew M, Chandravanshi BS, Redi-Abshiro M (2017) Preparative HPLC for large scale isolation, and salting-out assisted liquid-liquid extraction based method for HPLC-DAD determination of khat (Catha edulis Forsk) alkaloids. Chem Cent J 11:107. https://doi.org/10.1186/s13065-017-0337-6

43. Bedassa T, Megersa N, Gure A (2017) Salting-out assisted liquid-liquid extraction for the determination of multiresidue pesticides in alcoholic beverages by high performance liquid chromatography. Sci J Anal Chem 5(3):38-45

44. Kummerer K (2009) Antibiotics in the aquatic environment-Areview-part I. Chemosphere 75(4):417-434. https://doi.org/10.1016/j.chemospher e.2008.11.086

45. Rahmanian N, Ali SHB, Homayoonfard M, Ali NJ, Rehan M, Sadef Y, Nizami AS (2015) Analysis of physiochemical parameters to evaluate the drinking water quality in the state of perak, Malaysia. J Chem 2015. Article ID 716125. https://doi.org/10.1155/2015/716125

46. Alemu T, Mulugeta E, Tadese M, Kakaei K (2017) Determination of physicochemical parameters of "Hora" natural mineral water and soil in Senkele Kebele, Oromia Region, Ethiopia. Cogent Chem 3:1-13. https://doi. org/10.1080/23312009.2017.1354800

47. Verlicchi P, Galletti A, Petrovic M, Barcelo D, Al Aukidy M, Zambello E (2013) Removal of selected pharmaceuticals from domestic wastewater in an activated sludge system followed by a horizontal subsurface flow bedanalysis of their respective contributions. Sci Total Environ 454-455:411-425. https://doi.org/10.1016/j.scitotenv.2013.03.044

48. Aukidy AM, Verlicchi P, Voulvoulis N (2014) A framework for the assessment of the environmental risk posed by pharmaceuticals originating from hospital effluents. Sci Total Environ 493:54-64. https://doi.org/10.1016/j.scito tenv.2014.05.128

49. Ašperger D, Tišler V, Zrnčić M, Pavlović DM, Babić S, Horvat AJ, KaštelanMacan M (2014) HPLC-DAD-FLD determination of veterinary pharmaceuticals in pharmaceutical industry wastewater with precolumn derivatization using fluorescamine. Chromatographia 77:1059-1066. https://doi. org/10.1007/s10337-014-2685-x

50. Wei R, Ge F, Chen M, Wang R (2012) Occurrence of ciprofloxacin, enrofloxacin, and florfenicol in animal wastewater and water resources. J Environ Quality 41(5):1-6. https://doi.org/10.2134/jeq2012.0014

51. Babic S, Pavlovic MD, Asperger D, Perisa M, Zrncic M, Horvat AJ, KastelanMacan M (2010) Determination of multi-class pharmaceuticals in wastewater by liquid chromatography-tandem mass spectrometry (LC-MS-MS). J Anal Bioanal Chem 398(3):1185-1194. https://doi.org/10.1007/s0021 6-010-4004-1

52. Afonso-Olivares C, Torres-Padrón E, Sosa-Ferrera Z, Santana-Rodríguez $J$ (2013) Assessment of the presence of pharmaceutical compounds in seawater samples from coastal area of Gran Canaria Island (Spain). Antibiotics 2:274-287. https://doi.org/10.3390/antibiotics2020274 